Check for updates

Cite this: RSC Adv., 2017, 7, 38091

\title{
Antibacterial and biocompatible ABA-triblock copolymers containing perfluoropolyether and plant-based cardanol for versatile coating applications $\dagger$
}

\begin{abstract}
Yong-Seok Choi, $\$^{a}$ Na Kyung Kim,,$^{a}$ Hyo Kang, ${ }^{b}$ Hyun-Ki Jang, ${ }^{c}$ Myungkyung Noh, ${ }^{c}$ Jinseok Kim, ${ }^{a}$ Da-Jung Shon, ${ }^{a}$ Byung-Soo Kim ${ }^{\text {ac }}$ and Jong-Chan Lee (D) *a

ABA-triblock copolymers (PHCPMF\#s, where \# is the feed ratio of a monomer to an initiator) were prepared via atom transfer radical polymerization (ATRP), using modified perfluoropolyether (PFPE) as a macroinitiator ( $\mathrm{Br}$-PFPE-Br) to form the $\mathrm{B}$ block, and 2-hydroxy-3-cardanylpropyl methacrylate (HCPM) as a monomer to form the A blocks. Physically stable and transparent cross-linked PHCPMF\# (C-PHCPMF\#) films could be prepared on a silicon wafer using spin coating, followed by UV irradiation to form the cross-linked structure. C-PHCPMF\# showed bactericidal properties and bacterial adhesion resistance. The bacterial adhesion resistance of the PHCPMF\# films was found to closely correlate with the low surface energy and water contact angle hysteresis. In particular, the C-PHCPMF5 film, containing about two HCPM units in the A block, shows excellent biocidal/bacterial adhesion resistance and cell viability because it has an optimum amount of biocidal HCPM units, and a sufficient amount of

biocompatible PFPE units to impart a low surface energy.
\end{abstract}

Received 13th July 2017

Accepted 27th July 2017

DOI: $10.1039 / \mathrm{c} 7 \mathrm{ra0} 07689 \mathrm{~d}$

rsc.li/rsc-advances

\section{Introduction}

Inhibition of bacterial adhesion on polymer surfaces is a very important line of research, especially in the field of biomedical applications, because bacteria on surgical equipment and medical devices (even in small amounts) is the main cause of infectious complications acquired in hospitals. ${ }^{1-3}$ Fluoropolymers such as perfluoroalkyl polymers and perfluoropolyether (PFPE) are known to effectively prevent bacterial adhesion due to their low surface energy, which originates from the fluorine atoms. $^{4-6}$ In particular, PFPE derivatives have been widely studied for their biomedical applications, because of their good thermal and chemical stability, biocompatibility, and high oxygen permeability, as well as excellent bacterial fouling resistance. ${ }^{7,8}$ For example, cross-linked PFPE elastomers could be prepared by mixing with functional monomers, followed by UV or heat-induced radical cross-linking reaction; and they

\footnotetext{
${ }^{a}$ School of Chemical and Biological Engineering, Institute of Chemical Processes, Seoul National University, 599 Gwanak-ro, Gwanak-gu, Seoul 151-744, Republic of Korea. E-mail: jongchan@snu.ac.kr

${ }^{b}$ Dong-A University, 37 Nakdong-Daero 550 beon-gil, Saha-gu, Busan 604-714, Republic of Korea

'Interdisciplinary Program for Bioengineering, Seoul National University, Shilim-9Dong, Gwanak-Gu, Seoul 151-744, Republic of Korea

$\dagger$ Electronic supplementary information (ESI) available. See DOI: 10.1039/c7ra07689d

\$ These authors contributed equally to this work.
}

showed good biocompatibility, bio-stability, and bio-fouling resistance. ${ }^{9-13}$

The adhesion of bacteria could also be reduced using bactericidal polymers as the coating materials. ${ }^{14-16}$ In particular, biocidal materials from natural resources have drawn much attention, due to their biocompatibility and eco-friendly properties. ${ }^{17-20}$ Cardanol is one of the bactericidal materials from plant-based resources, ${ }^{21}$ and we discovered that methacrylate polymers with cardanol moieties exhibit excellent bactericidal properties. ${ }^{22}$ Recently, we further discovered that polymers containing both fouling-resistant dopamine and bactericidal cardanol moieties can be used as coating materials for water treatment membranes. ${ }^{23}$

In this study, we designed and synthesized ABA tri-block copolymers having multi-functional properties of bactericidal property, bacterial adhesion resistance, and good biocompatibility, using plant-based 2-hydroxy-3-cardanylpropyl methacrylate (HCPM) as a monomer, and modified PFPE with 2-bromoisobutyryl bromide as a macroinitiator. Cross-linked ABA-triblock copolymers could be prepared using a spincoating method, followed by an UV curing process; and their surface properties, bacterial adhesion resistance, bactericidal properties, and biocompatibility were investigated. In addition, the correlation between surface properties and bacterial adhesion resistance of the polymers was systematically investigated. To the best of our knowledge, this is the first report on the synthesis of linear block copolymers composed of cardanol 
moieties having antibacterial property, and fluorinated moiety having low surface energy and biocompatible property.

\section{Experimental}

\section{Materials}

Cardanol was provided by Mercury Co., Ltd. (India). Glycidyl methacrylate and triethylamine were purchased from TCI Co., Ltd. (Japan). FLUOROLINK® E10H, which is perfluoropolyether (PFPE) with linear structure and characterized by the presence at both ends of an ethoxyilic chain terminated with an $-\mathrm{OH}$ group, was purchased from Solvay Solexis. 2-Bromoisobutyryl bromide (98\%), copper(I) bromide (CuBr) (98\%), $N, N, N^{\prime}, N^{\prime}, N^{\prime \prime}$ pentamethyldiethylenetriamine (PMDETA) (99\%), and $\alpha, \alpha, \alpha-$ trifluorotoluene (TFT) ( $\geq 99.0 \%)$ were purchased from SigmaAldrich Co., Ltd. (USA). TFT was distilled over calcium hydride before use. Potassium hydroxide $(\mathrm{KOH}), N, N$-dimethylacetamide (DMAc) were obtained from Daejung Chemicals \& Metals Co., Ltd. (Korea). Escherichia coli (E. coli; ATCC 8739) and Pseudomonas aeruginosa PA01 (P. aeruginosa; ATCC 15692) were obtained from American Type Culture Collection (ATCC). BactoTM Agar, DifcoTM Nutrient Broth, and DifcoTM Tryptic Soy Broth were obtained from Becton, Dickinson and Company (BD). All other reagents were used as received from standard vendors. Human dermal fibroblasts (HDFs) were purchased from Lonza. 2-Hydroxyl-3-cardanylpropyl methacrylate (HCPM) was synthesized according to the procedure described elsewhere as shown in Fig. 1(a) and outlined in ESI. $\dagger^{22}$

\section{Synthesis of PFPE-macroinitiator (Br-PFPE-Br)}

FLUOROLINK® E10H $\left(M_{\mathrm{n}} \approx 1600,5.00 \mathrm{~g}, 3.13 \mathrm{mmol}\right)$ and $\alpha, \alpha, \alpha$-trifluorotoluene (TFT) $(50 \mathrm{~mL})$ were added to a roundbottomed flask with a magnetic stirring bar under nitrogen and cooled to $0{ }^{\circ} \mathrm{C}$. A solution of 2-bromoisobutyryl bromide $(2.7 \mathrm{~mL}, 21.88 \mathrm{mmol})$ in TFT $(5 \mathrm{~mL})$ was added to the $\mathrm{E} 10 \mathrm{H}$ solution by dropwise over $5 \mathrm{~min}$. The mixture was stirred at $0{ }^{\circ} \mathrm{C}$ for $3 \mathrm{~h}$, followed by $18 \mathrm{~h}$ at room temperature. The crude product was filtered and then TFT was evaporated in a lowpressure environment, followed by washing with methanol several times. Residual methanol in the product was removed by evaporation in a low-pressure environment and then filtered again. The final product was light-yellow oil (2.6 g, 40.4\%).

${ }^{1} \mathrm{H}$ NMR (300 MHz, $\mathrm{CDCl}_{3}$, trimethylsilane (TMS) ref): $\delta=1.93$ (s, $\left.-\mathrm{OCH}_{2} \mathrm{CH}_{2} \mathrm{OC}(\mathrm{O}) \mathrm{C}\left(\mathrm{CH}_{3}\right)_{2} \mathrm{Br}\right)$, 3.54-4.00 (m, $-\mathrm{CF}_{2} \mathrm{OCF}_{2} \mathrm{CH}_{2}$ $\left.\left(\mathrm{OCH}_{2} \mathrm{CH}_{2}\right)_{n-1} \mathrm{OCH}_{2} \mathrm{CH}_{2} \mathrm{OC}(\mathrm{O}) \mathrm{C}\left(\mathrm{CH}_{3}\right) \mathrm{Br}\right), \quad 4.33 \quad(\mathrm{~s}, \quad-\mathrm{OC}(\mathrm{O})$ $\left.\mathrm{C}\left(\mathrm{CH}_{3}\right)_{2} \mathrm{Br}\right)$.

\section{Synthesis of ABA-triblock copolymers (PHCPMF\#)}

The ABA-triblock copolymers containing PFPE and HCPM blocks is named as PHCPMF\#, where \# is the feed ratios of HCPM and Br-PFPE-Br. The following procedure was used for the preparation of PHCPMF10. Br-PFPE-Br $(0.50 \mathrm{~g}, 0.26 \mathrm{mmol})$, HCPM $(0.58 \mathrm{~g}, 2.6 \mathrm{mmol})$, and TFT $(10 \mathrm{~mL})$ were placed into a $100 \mathrm{~mL}$ Schlenk flask equipped with a magnetic stirring bar and the mixture was deoxygenated by three freeze-pump-thaw cycles. After $\mathrm{CuBr}$ (74 mg, $0.52 \mathrm{mmol}$ ) was introduced to the (a)

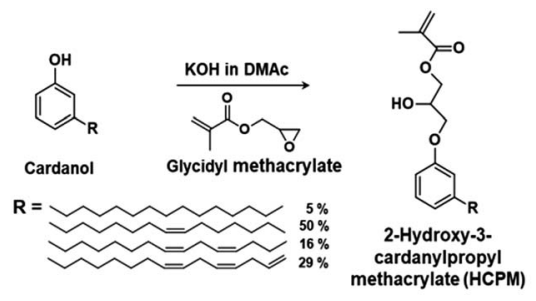

(b)

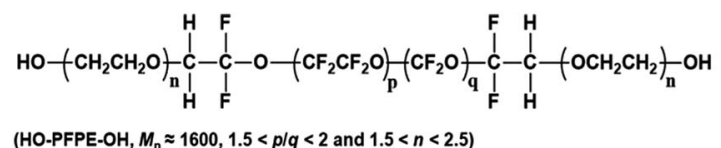

(c)

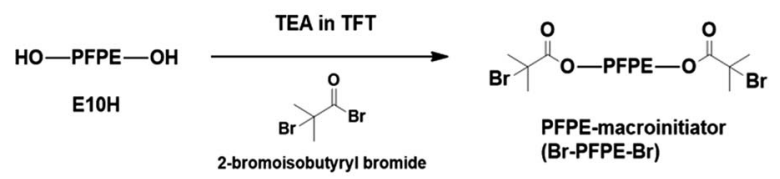

(d)
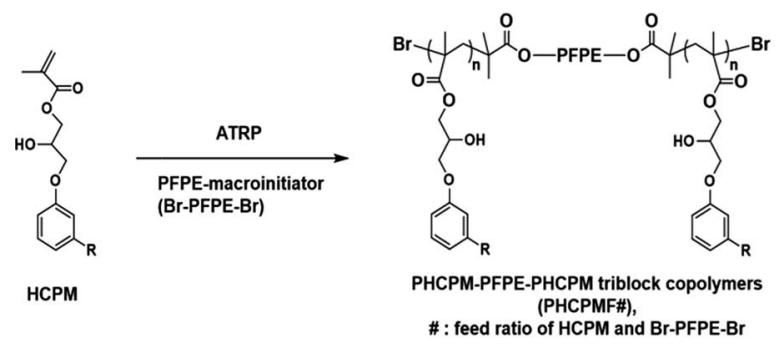

Fig. 1 (a) Synthesis of 2-hydroxy-3-cardanylpropyl methacrylate (HCPM). (b) Chemical structure of E10H. Synthesis of (c) PFPE-macroinitiator (Br-PFPE-Br) and (d) PHCPM-PFPE-PHCPM triblock copolymers (PHCPMF\#).

flask under the $\mathrm{N}_{2}$ flow, the flask was subjected to two more freeze-pump-thaw cycles and backfilled with $\mathrm{N}_{2}$ to restore atmospheric pressure with the inert environment. Then the flask was placed into an oil bath thermostatted at $70{ }^{\circ} \mathrm{C}$. Finally, PMDETA (108 $\mu \mathrm{L}, 0.52 \mathrm{mmol})$ was injected into the reaction flask to initiate polymerization. After $18 \mathrm{~h}$ of polymerization, the solution was exposed to the air. The mixture was diluted with TFT and passed through a neutral alumina column to remove copper catalysts. After removing most of the solvent using evaporator, the solution was precipitated using methanol as the non-solvent. The dissolution-precipitation procedure was repeated for three times, yielding light-yellow solid $(0.6 \mathrm{~g})$. The monomer conversion determined by ${ }^{1} \mathrm{H}$ NMR was found to be 78.5\%. Other PHCPMF\#s were prepared using the same procedure except the amount of monomer as shown in Table 1.

\section{Preparation of cross-linked PHCPMF\# (C-PHCPMF\#) films}

$1 \mathrm{wt} \%$ polymer solutions in THF was coated on glass or silicon wafer substrates by the spin-coating method (3000 rpm, $30 \mathrm{~s}$ ) or the drop casting method, and then dried in vacuum overnight. The coatings were irradiated with $21700 \mathrm{~mW} \mathrm{~cm} \mathrm{~cm}^{-2} \mathrm{UV}$ light (B-100AP ultraviolet lamp, UVP Inc., USA) at a distance of $5 \mathrm{~cm}$ for 2 days under air at room temperature to prepare cross-linked PHCPMF\# (named as C-PHCPMF\#) films. 
Table 1 Results of the synthesis of the PHCPMF\#s from different monomer and initiator feeding ratios

\begin{tabular}{|c|c|c|c|c|c|c|}
\hline Samples & {$[\mathrm{M}] /[\mathrm{I}]$} & Conversion $^{a}(\%)$ & The number of repeating unit in $\mathrm{A} \mathrm{block}^{a}$ & Calculated $M_{\mathrm{n}}{ }^{a}$ & $M_{\mathrm{n} / \mathrm{w}}^{b}$ & $\mathrm{PDI}^{b}$ \\
\hline PHCPMF5 & 5 & 79.0 & 2.0 & 3700 & $6800 / 9900$ & 1.45 \\
\hline PHCPMF10 & 10 & 78.5 & 3.9 & 5400 & $7300 / 10300$ & 1.42 \\
\hline
\end{tabular}

${ }^{a}$ Determined by ${ }^{1} \mathrm{H}$ NMR. ${ }^{b}$ Determined by GPC using refractive index (RI) detector (THF).

\section{Bactericidal activity}

The bactericidal activity of the C-PHCPMF\# films was investigated using film attachment test against Escherichia coli (E. coli; ATCC 8739). To prepare the bacteria suspension, E. coli cells were cultured in the nutrient broth (NB) solutions at $37^{\circ} \mathrm{C}$ for $18 \mathrm{~h}$. A representative colony was lifted off with a platinum loop, placed in $30 \mathrm{~mL}$ of nutrient broth, and incubated with shaking at $37{ }^{\circ} \mathrm{C}$ for $18 \mathrm{~h}$. After washing twice with phosphate buffer saline (PBS), they were re-suspended in PBS to yield $1 \times 10^{6}$ colony forming unit (CFU) per $\mathrm{mL} .{ }^{24}$ Bacterial cell concentration was estimated by measuring the absorbance of cell dispersions at $600 \mathrm{~nm}$ and referenced to a standard calibration curve. An optical density of 0.1 at $600 \mathrm{~nm}$ is approximately equivalent to $10^{8} \mathrm{CFU}$ per $\mathrm{mL} .^{25}$ To evaluate the bactericidal activity of polymer films, $0.1 \mathrm{~mL}$ of the bacterial suspension was dropped on the surfaces of the polymer films $(2 \mathrm{~cm} \times 2 \mathrm{~cm})$ located in a Petri dish and the films were covered by OHP films having the same size to ensure full contact. After $24 \mathrm{~h}$ at $25{ }^{\circ} \mathrm{C}, 0.9 \mathrm{~mL}$ of PBS was poured into the Petri dishes that contain the samples. After vigorous shaking to detach adherent cells from the films, the solution mixture was transferred to micro tube. The resulting solution was serially diluted and then $0.1 \mathrm{~mL}$ of each diluent was spread on the agar plates. Viable microbial colonies were counted after incubated for $18 \mathrm{~h}$ at $37{ }^{\circ} \mathrm{C}$. Each test was repeated at least three times. Bactericidal activity was calculated as follows:

$$
\text { Bactericidal activity }(\%)=100 \times\left(N_{0}-N_{\mathrm{i}}\right) / N_{0}
$$

where $N_{0}$ is bacterial CFU of blank and $N_{\mathrm{i}}$ is bacterial CFU of tested sample. ${ }^{26}$

\section{Bacterial adhesion test}

Pseudomonas aeruginosa PA01 (P. aeruginosa; ATCC 15692) containing a plasmid with a green fluorescent protein (GFP) gene was cultured overnight in Luria-Bertani (LB) broth with $100 \mathrm{~g} \mathrm{~mL}{ }^{-1}$ of carbenicillin at $37^{\circ} \mathrm{C}$. The culture was centrifuged and washed with sterile PBS. Cells were resuspended to an optical density at $600 \mathrm{~nm}$, and then they were diluted $1: 100 \mathrm{in}$ PBS corresponding to $10^{7}$ colony forming units (CFU) per $\mathrm{mL}$. Polymer films $(1 \mathrm{~cm} \times 1 \mathrm{~cm})$ were prepared in triplicate and soaked in $2 \mathrm{~mL}$ of bacterial suspension in 24-well culture dish for $24 \mathrm{~h}$ at $110 \mathrm{rpm}, 25^{\circ} \mathrm{C}$. Samples were gently rinsed twice with sterile distilled water in order to remove loosely attached cells. To evaluate surface coverage (the percentage of surface area covered with adhered cells), a fluorescence microscope (DS-2U,
Nikon, Japan) measurement was performed using the image software (i-solution, IMT Technologies, USA).

\section{Cytotoxicity assays}

HDFs were cultured in Dulbecco's Modified Eagle's Medium (DMEM, Gibco BRL, Gaithersburg, MD, USA) supplemented with $10 \%(\mathrm{v} / \mathrm{v})$ fetal bovine serum (FBS, Gibco BRL), and 100 units per $\mathrm{mL}$ penicillin (Gibco BRL) and $100 \mathrm{mg} \mathrm{mL}$ streptomycin (Gibco BRL). To test biocompatibility of CPHCPMF\# films, cells were seeded on the polymer films at a density of $5 \times 10^{3}$ cells per $\mathrm{cm}^{2}$ and maintained in DMEM (Gibco BRL) supplemented with 10\% (v/v) FBS (Gibco BRL) 100 units per $\mathrm{mL}$ penicillin (Gibco BRL) and $100 \mathrm{mg} \mathrm{mL}$ streptomycin (Gibco BRL).

The viability of HDFs was evaluated using a colorimetric test based on the uptake of neutral red (3-amino-7-dimethylamino2-methylphenazine hydrochloride) dye into viable cells. Briefly, HDFs were rinsed with PBS and incubated for $3 \mathrm{~h}$ at $37^{\circ} \mathrm{C}$ in DMEM medium containing neutral red $\left(50 \mu \mathrm{g} \mathrm{mL}{ }^{-1}\right.$, Sigma). After removing the medium, an aqueous solution of $1 \%(\mathrm{v} / \mathrm{v})$ acetic acid and $50 \%(\mathrm{v} / \mathrm{v})$ ethanol was added to extract the dye. After $5 \mathrm{~min}$ of incubation at room temperature, the absorbance was read at $540 \mathrm{~nm}$ by a spectrophotometer. Viability of HDFs was expressed as a percentage of the absorbance of positive control of bare glass. The morphology of HDFs was measured by using a light microscope (IX71, Olympus, Tokyo, Japan).

Live and dead cells were detected with fluorescence microscopy after staining with fluorescein diacetate (FDA, Sigma Aldrich) and ethidium bromide (EB, Sigma-Aldrich) at day 1 and 3 after seeding. The cells cultured on the blend films were incubated in FDA/EB $\left(5 \mu \mathrm{g} \mathrm{mL} \mathrm{m}^{-1}, 10 \mu \mathrm{g} \mathrm{mL}^{-1}\right.$, respectively) for $5 \mathrm{~min}$ at $37^{\circ} \mathrm{C}$ and then washed twice in PBS. Dead cells stained red due to the nuclear permeability to EB. Viable cells, capable of converting the non-fluorescent FDA into fluorescein, were stained green. After staining, the samples were examined using a fluorescence microscope (IX71, Olympus, Tokyo, Japan).

\section{Characterization}

The chemical structures of the monomers and polymers were characterized by ${ }^{1} \mathrm{H}$ NMR spectroscopy (ZEOL LNM-LA 300, $300 \mathrm{MHz})$ using $\mathrm{CDCl}_{3}$ as a solvent. Molecular weight $\left(M_{\mathrm{n}}, M_{\mathrm{w}}\right)$ and polydispersity index (PDI) were analyzed by gel permeation chromatography (GPC) using the polystyrene standard. HPLC grade THF (J. T. Baker) was used as an eluent at a flow rate of $1.0 \mathrm{~mL} \min ^{-1}$ and $30{ }^{\circ} \mathrm{C}$. Infrared (IR) spectra were recorded on a Nicolet 6700 spectrophotometer (Thermo Scientific, USA) 
using attenuated total reflectance (ATR) equipment (FT-IR/ ATR). UV-Vis spectra were measured by Agilent 8453 UVvisible spectrometer at room temperature. Tapping-mode AFM measurements were performed using a scanning probe microscopy (INNV-BASE, Veeco, USA). Silicon cantilevers with the normal resonance frequency of $300 \mathrm{kHz}$ (TAP300Al-G series, Budget Sensors, Innovative Solutions Bulgaria Ltd.) were used. The surface composition of the membranes was analyzed by X-ray photoelectron spectroscopy (XPS, Physical Electronics, Quantum 2000) using Mg Ka (1254.0 eV) as the radiation source, and survey spectra were collected over a range of $0-1100 \mathrm{eV}$. Contact angles of water and diiodo-methane on polymer surfaces in were measured by a Kruss DSA100 contact angle analyzer interfaced to computer running drop shape analysis software. The contact angles for each sample were measured more than five times on five independently prepared polymer films, and the average values were used as the data. The OwensWendt-Rabel-Kaelble (OWRK) method was used for calculating surface energy of the polymer films. ${ }^{27,28}$

\section{Results and discussion}

\section{Synthesis of Br-PFPE-Br and HCPM monomer}

Fig. 1(b) shows that Fluorolink ${ }^{\circledR}$ E10H is a perfluoropolyether (PFPE) that has hydroxy oligo(oxyethylene) end groups. The average molecular weight $\left(M_{\mathrm{n}}\right)$ of the PFPE is about 1600, and the polymer composition ratios indicated by $p / q$ and $n$ are $1.5<p / q<2$ and $1.5<n<2.5$, respectively. ${ }^{29}$ PFPE-macroinitiator (Br-PFPE$\mathrm{Br}$ ) was prepared from the reaction of the PFPE with 2-bromoisobutyryl bromide using triethylamine (TEA) as a base catalyst, and $\alpha, \alpha, \alpha$-trifluorotoluene (TFT) as a solvent (Fig. 1(c)). The chemical structure of Br-PFPE-Br was confirmed by ${ }^{1} \mathrm{H}$ NMR and FT-IR/ATR. Fig. 2(b) shows characteristic peaks of protons at both ends of $\mathrm{Br}-\mathrm{PFPE}-\mathrm{Br}$ at $1.93\left(-\mathrm{OCH}_{2} \mathrm{CH}_{2} \mathrm{OC}(\mathrm{O}) \mathrm{C}\left(\mathrm{CH}_{3}\right)_{2} \mathrm{Br}\right)$ and $4.33\left(-\mathrm{OC}(\mathrm{O}) \mathrm{C}\left(\mathrm{CH}_{3}\right)_{2} \mathrm{Br}\right) \mathrm{ppm}$, indicating that the hydroxyl end groups of the PFPE successfully reacted with 2-bromoisobutyryl bromide. In addition, FT-IR spectra (Fig. S1 $\dagger$ ) show that the characteristic $\mathrm{O}-\mathrm{H}$ vibration peak at $3500 \mathrm{~cm}^{-1}$ of the PFPE disappeared after the reaction, demonstrating that all the hydroxyl end groups of the PFPE reacted with 2-bromoisobutyryl bromide.

2-Hydroxyl-3-cardanylpropyl methacrylate (HCPM) was synthesized according to the procedure described in our previous work (see the ESI $\dagger$ ). ${ }^{22}$ Briefly, the phenolic -OH group of cardanol reacted with the epoxy group of glycidyl methacrylate in the presence of potassium hydroxide $(\mathrm{KOH})$ at $25^{\circ} \mathrm{C}$, and ${ }^{1} \mathrm{H}$ NMR (Fig. 2(c)) confirmed the structure of HCPM monomer. The methacrylate group in HCPM can be used for radical polymerization, and the unsaturated hydrocarbon chains in the cardanol moiety can be utilized for the self-cross-linking reaction.

Synthesis of ABA-triblock copolymers containing plant-based cardanol and perfluoropolyether moieties (PHCPMF\#s)

ABA-triblock copolymers (PHCPMF\#s, where \# is the feed ratios of HCPM and $\mathrm{Br}-\mathrm{PFPE}-\mathrm{Br}$ ) were prepared via atom transfer radical polymerization (ATRP), using HCPM as a monomer, and (a)

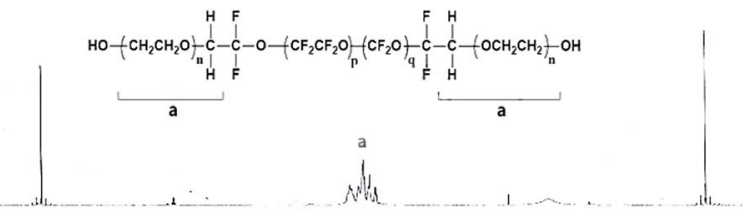

(b)

b)

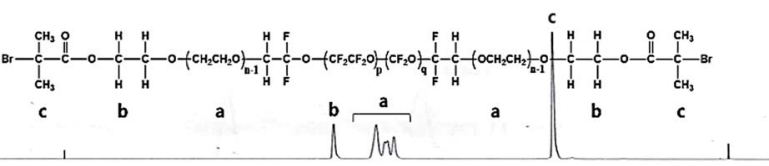

(c)

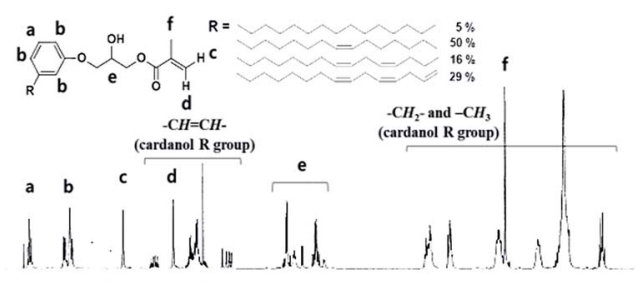

(d)

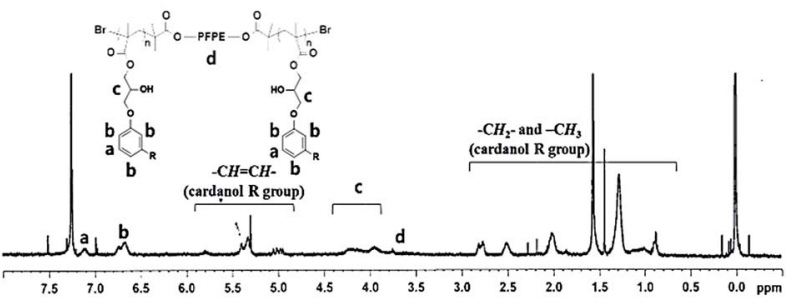

Fig. $2{ }^{1} \mathrm{H}$ NMR spectrum of (a) E10H, (b) Br-PFPE-Br, (c) HCPM, and (d) HCPMF30.

$\mathrm{Br}-\mathrm{PFPE}-\mathrm{Br}$ as an initiator, in the presence of $\mathrm{CuBr} / \mathrm{PMDETA}$ (Fig. 1(d)). In order to prepare well-defined polymers using a living radical polymerization (LRP) system such as ATRP, it is important to use a suitable initiator, solvent, monomer, and catalyst. Since $\alpha$-bromoisobutyryl group is one of the suitable initiating groups that can initiate polymerization of various methacryl monomers in ATRP, such as HCPM monomer, ${ }^{30}$ we reacted 2-bromoisobutyryl bromide with PFPE.

Fig. 2(d) shows the ${ }^{1} \mathrm{H}$ NMR spectrum with assignments of the respective peaks of PHCPMF30. The proton peaks observed at $\delta=6.70$ and 7.11 were clearly assigned to the protons at the meta position of the aromatic rings in the HCPM. Additionally, the peaks from the unsaturated hydrocarbon chain (R group in Fig. 2(d)) of the cardanol moieties were observed at 4.80$5.90 \mathrm{ppm}$, demonstrating that the unsaturated hydrocarbons in the cardanol moiety remained intact during the ATRP process. The proton peaks from PFPE (1.93, 3.5-4.0, and $4.33 \mathrm{ppm}$ ) overlapped those in the cardanol moiety. Table 1 shows monomer conversions and the number of repeating units of HCPM on each side of the B block in the PHCPMF\#s prepared using different feed ratios of HCPM and Br-PFPE-Br (\#) via ATRP. Since the ${ }^{1} \mathrm{H}$ NMR peaks from HCPM units (A block) and PFPE (B block) overlap, Fig. 2(d) shows that the conversion of HCPM into PHCPMF\# and the number of repeating units of HCPM in PHCPMF\# could not be calculated from the ${ }^{1} \mathrm{H}$ NMR spectra of PHCPMF\#s. Therefore, the ${ }^{1} \mathrm{H}$ NMR spectrum of the reaction mixture obtained after $18 \mathrm{~h}$ polymerization of $\mathrm{Br}-$ PFPE-Br and HCPM was used to obtain the conversion and the compositions, as follows: 


$$
\text { HCPM conversion }(\%)=\left(1-I_{\mathrm{e}} / I_{\mathrm{a}}\right) \times 100
$$

Number of repeating units of $\mathrm{HCPM}=(C \times[\mathrm{M}]) /$

$$
(2 \times 100 \times[\mathrm{I}])
$$

where, $I_{\mathrm{e}}$ and $I_{\mathrm{a}}$ are the intensities of the e and a proton peaks, respectively, in ${ }^{1} \mathrm{H}$ NMR of PHCPMF\#s of the reaction mixture as shown in Fig. S2, $\dagger$ and $C$ is the HCPM conversion. [M] and [I] are the initial concentration of HCPM monomer and Br-PFPE$\mathrm{Br}$ in the ATRP process, respectively. The relative molecular weights of the polymers were analyzed by GPC coupled with a refractive index (RI) detector using THF as the eluent, and they could also be calculated from the ${ }^{1} \mathrm{H}$ NMR results (Table 1). Since the experimental GPC molecular weight is the relative value in comparison with those of polystyrene standards, discord between the experimental and calculated molecular weights can easily be expected. ${ }^{30,31}$ All PHCPMF\#s were found to be soluble in the THF, although Br-PFPE- $\mathrm{Br}$ is not; and their relative molecular weights $\left(M_{\mathrm{n}}\right)$ increase with increasing number of repeating units of HCPM on each side of the B block in the polymers, indicating the incorporation of non-polar cardanol moiety producing ABA-triblock copolymers.

\section{Preparation of cross-linked PHCPMF\# (C-PHCPMF\#) films}

Previously, it was demonstrated that polymers with cardanol moiety could be cross-linked by heat or UV irradiation, and their cross-linked structures could enhance the mechanical strength of the polymers. ${ }^{32-35}$ Cross-linked PHCPMF\# (C-PHCPMF\#) films were prepared by a spin-coating method (3000 rpm, $30 \mathrm{~s}$ ) using $1.0 \mathrm{wt} \%$ of PHCPMF\# solutions in the THF, followed by UV irradiation for 2 days. After the UV irradiation process, the sticky state of PHCPMF\# changed to stable and glossy state, indicating that PHCPMF\# films successfully cross-linked after the UV irradiation. If high molecular weight PHCPMF\#s were available, it would be possible for physically stable PHCPMF\# films without the cross-linked structures to be prepared. However, to obtain high molecular weight PHCPMF\#, the content of HCPM moiety should further increase; then the content of PFPE moiety becomes too small to provide the antifouling property. Therefore PHCPMF\#s having a molecular weight in the range of 3000 to 13000 were intentionally synthesized, and they were then cross-linked to prepare the physically stable C-PHCPMF\# films.

Table 2 shows the surface compositions of the C-PHCPMF\# films that were characterized by XPS analysis. Since the HCPM moiety in the polymers contains larger carbon content than the PFPE moiety, the carbon contents of the C-PHCPMF\# films increase with the increase of molecular weight, because the

Table 2 XPS elemental composition (in at\%) of the surfaces of CPHCPMF\# films

\begin{tabular}{lcccc}
\hline Samples & C 1s & O 1s & F 1s & F/C \\
\hline C-PHCPMF5 & 49.94 & 15.97 & 34.10 & 0.68 \\
C-PHCPMF10 & 56.60 & 15.35 & 28.05 & 0.50 \\
C-PHCPMF30 & 65.85 & 14.08 & 20.07 & 0.30
\end{tabular}

number of repeating unit of HCPM on each side of the B block in the polymers increases. Since the HCPM moiety does not have any fluorine group, the atomic ratios of fluorine to carbon (F/C) of CPHCPMF\# films decreases with the increase of molecular weight.

Photographs (inset of Fig. 3) and UV-Vis spectra (Fig. 3) showed the physically stable C-PHCPMF\# films were transparent. The thickness of the films prepared using the spin coating method was in the $25-55 \mathrm{~nm}$ range. The transmittance values of the C-PHCPMF\# films are close to that of bare glass substrate (about $95 \%$ in the $340-800 \mathrm{~nm}$ range), regardless of the HCPM content. Therefore, the optical transparency of all of the C-PHCPMF\# films in the visible light region is good enough to use as optical thin films and coating applications.

\section{Bactericidal activity}

The bactericidal property of the C-PHPMCF\#s films was evaluated against Escherichia coli (E. coli, ATCC 8739) by a filmattached method based on standard ISO 22196:2011, using PMMA film as a negative control, and the cross-linked HCPM homopolymer (C-PHCPM) film as a positive control. Fig. 4(a) and (b) show the photographic results and the calculated bactericidal activity of the polymer films, respectively. Fig. 4(a) shows that there are a few or no bacterial colonies on the agar plates of C-PHCPMF\# and C-PHCPM films, and the bactericidal activity of C-PHCPMF5, C-PHCPMF10, C-PHCPMF30, and C-PHCPM films were found to be 99.94, 96.59, 99.07, and $99.57 \%$, respectively. Note that the bactericidal activity of C-PHCPMF5 film having only about two HCPM units at each end group (Table S1 $\dagger$ ) is close to that of C-PHCPM containing only biocidal HCPM unit. Previously, it was also found that the cardanol-containing polymers containing only a small content of HCPM unit can show bactericidal activity close to those having $100 \mathrm{~mol} \%$ of HCPM units. ${ }^{22,23}$

\section{Bacterial adhesion resistance}

The bacterial adhesion resistance of the C-PHCPMF\# films was evaluated using $P$. aeruginosa PA01 strain containing a plasmid

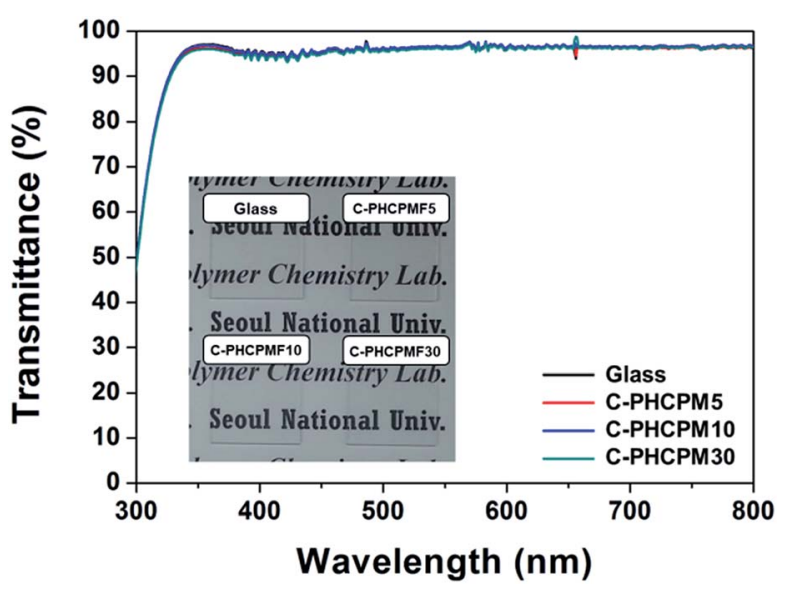

Fig. 3 UV-Vis spectra of the C-PHCPMF\# films on glass substrates. Inset is photograph of the C-PHCPMF\# films prepared by a spincoating method. 
(a)

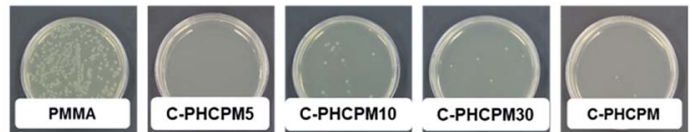

(b)

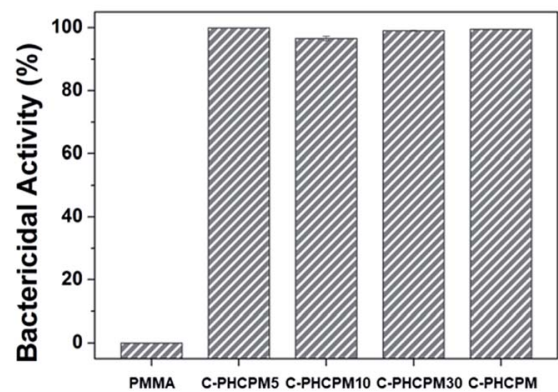

Fig. 4 (a) Photographs of C-PHPMCF5, C-PHCPMF10, C-PHCPMF30, C-PHCPM, and PMMA films via antibacterial test against E. coli. (b) Bactericidal activity of polymer films.

with a green fluorescent protein (GFP) gene, by observing the surface coverage from the fluorescence microscopy images of adhered bacteria after incubation for $24 \mathrm{~h}$. It is reasonable to use $E$. coli (ATCC 8739) as model bacteria in bacterial adhesion test, because $E$. coli was used as the model bacteria in the bactericidal test. However, SYTO9 and propidium iodide (PI), which are commonly used to stain live and dead E. coli, can also stain the surface of C-PHCPMF\# films, so that stained cells and polymers cannot be distinguished. The bacterial adhesion resistance of the non-cross-linked PHCPMF\# films was also evaluated, to investigate the effect of cross-linking on the bacterial adhesion property. The surface coverage of bacteria on the surfaces of the polymer films increases with the increase of molecular weight (or increasing the number of repeating units of HCPM). It is also notable that C-PHCPMF\# film exhibits superior bacterial adhesion resistance to that of the corresponding non-cross-linked PHCPMF\# film (Fig. 5). The effect of cross-linked structure on the bacterial adhesion resistance of the polymer films is discussed in detail later in this letter. Overall, it is clear that C-PHCPMF5 film, which has the smallest content of HCPM units, shows superior bacterial adhesion

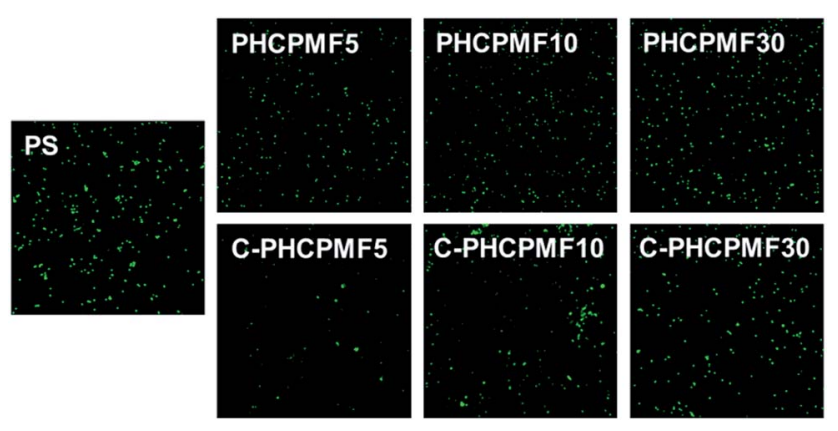

Fig. 5 Representative fluorescence microscope images (scale bar = $0.1 \mathrm{~mm}$ ) of adhered $P$. aeruginosa onto PHCPMF\#, C-PHCPMF\#, and control polymer surfaces. resistance, when compared with other C-PHCPMF\#s and noncross-linked PHCPMF5 films.

Polymer films with bactericidal property effectively kill bacteria in the initial state, but accumulated dead bacteria on the surface can decrease the bactericidal activity of the polymers, because they can prevent the interaction of the biocidal surface with bacteria. Therefore in addition to the bactericidal properties, the bacterial adhesion-resistant properties are required to effectively prevent bacterial fouling on the polymer surfaces. There have been many studies on the development of multi-functional materials with antifouling and bactericidal properties, and their antibacterial properties are superior to those of materials with only bactericidal property. ${ }^{36-38}$ Since the PHCPMF\#s designed in this study have both cardanol moiety as an antibacterial site and PFPE moiety as an antifouling site, we strongly believe that C-PHCPMF\# films should be very effective materials for antibacterial coating applications. In particular, it was found that among the PHCPMF\#s, PHCPMF5 is the most suitable material to use for antibacterial and antifouling coating applications, as Fig. 4 and 5 show.

\section{Surface properties and antifouling mechanism}

Static and dynamic contact angle analyses were used to analyze the surface properties to understand the bacterial fouling resistance of the C-PHCPMF\# films (Table 3). Water and diiodomethane static contact angles of the PHCPMF\# and CPHCPMF\# films increase with increase of the content of PFPE moiety, or with decrease of the number of repeating units of HCPM. The Wu and Owens-Wendt-Rabel-Kaelble (OWRK) method was used to obtain the surface energies of the PCHPMF\# and C-PHCPMF\# films from the CA results to study the relation between antifouling property and surface energies of the polymer films. Surface energy of the PHCPMF\# and C-PHCPMF\# films decreases with the decrease of the number of repeating units of HCPM, although the decrease is not much, and energy values are in the $22-25 \mathrm{mN} \mathrm{m}^{-1}$ range. In addition, the surface energy values of corresponding non-crosslinked PHCPMF\# and cross-linked C-PHCPMF\# films are almost identical, indicating that the cross-linking structure does not affect the surface energy of the PHCPMF\# films. The advancing and receding contact angles (dynamic contact angles) of deionized water were also measured at room temperature and ambient relative humidity (Table 3). In the case of the PHCPMF\# films, water contact angle hysteresis (CAH) values could not be obtained, due to their very low receding contact angles. In contrast, the receding CA of the C-PHCPMF\# films could be measured, and the CAH values of the C-PHCPMF\# films decrease with increase of the number of repeating units of HCPM. In particular, C-PHCPMF5 film exhibits relatively lower $\mathrm{CAH}\left(31.4^{\circ}\right)$ than the other C-PHCPMF\# films (41.0 and $42.1^{\circ}$ for C-PHCPMF10 and C-PHCPMF30 films, respectively).

It is well known that bacterial adhesion on the surface relates to the surface energy of the materials. According to the Baier curve, a material's critical surface energy is between 20 and $30 \mathrm{mN} \mathrm{m}^{-1}$, and preferably between 22 and $24 \mathrm{mN} \mathrm{m}^{-1}$ for 
Table 3 Static contact angles, surface energies, dynamic contact angles of water, and hysteresis of PHCPMF\# and C-PHCPMF\# films

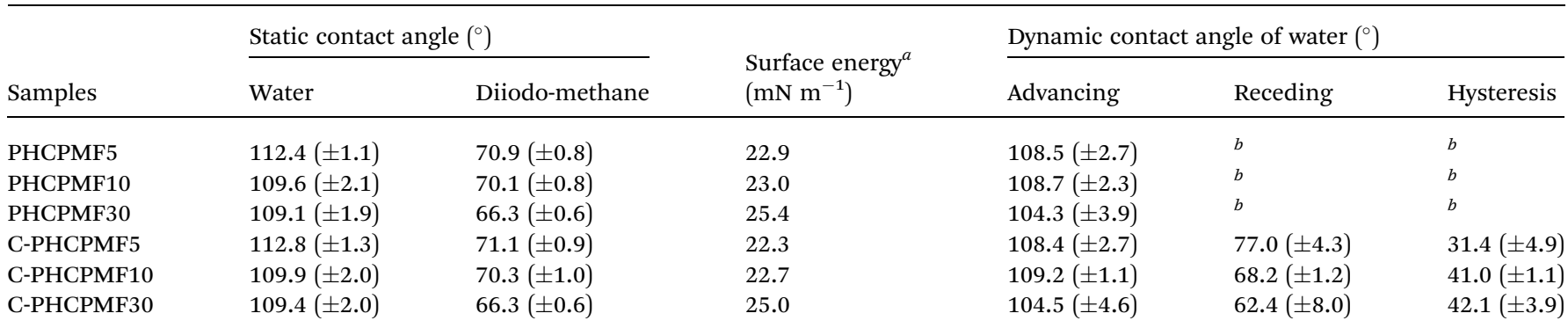

${ }^{a}$ Calculated using the Owens-Wendt-Rabel-Kaelble (OWRK) method. ${ }^{b}$ Because their receding contact angles were too small to be observed, hysteresis values could not be obtained.

minimum biofouling on the surface of substrates. ${ }^{39}$ Therefore it is obvious that the surface energies of the PHCPMF\# and C-PHCPMF\# films correspond to the critical surface energy shown in the Baier curve for minimum biofouling. However, the results of bacterial adhesion test in this study are somewhat different from the Baier theory. Fig. 5 shows that C-PHCPMF\# films have better bacterial adhesion resistance than PHCPMF\# films, although they have almost the same surface energy values. Therefore, it is very obvious that surface energy is not the only indicator to explain the antifouling properties for low-surface energy materials. ${ }^{40-42}$ Schmidt et al. reported that biofouling on the surfaces of fluorinated polymers can also be correlated with receding water CA and contact angle hysteresis (CAH), which are strongly affected by the surface penetration and surface reconstruction..$^{41}$ For example, some of the fluorinated polymers with very low surface energy might not have an effective biofouling property if the fluorinated chains are restructured by contact with polar liquids including water, ${ }^{40-42}$ because the reconstructed chains can result in small water CA and large $\mathrm{CAH}^{41,43,44}$ We could expect to attribute the difference of CAH values between PHCPMF\# and C-PHCPMF\# films to the difference between cross-linked structures; the cross-linking structure that originates from unsaturated long chains in the cardanol moiety increases bacterial adhesion resistance by reducing $\mathrm{CAH}$, as well as the stability for coating applications. It is also well known that cross-linked chains have less chain mobility than linear ones; then, the restructuring by contact with polar solvent can be minimized, and the low surface energy property can be maintained. ${ }^{41}$

\section{Biocompatibility}

To investigate the biocompatibility of the C-PHCPMF\# films, the viability and proliferation of HDFs on C-PHCPM\# films were investigated by neutral red assay. Fig. 6(a) and (b) show optical microscopy images of HDFs cultured on the C-PHCPMF\# films and bare glass for 1 and 3 days, respectively. The density of the HDFs on all the samples increases with time, indicating that C-PHCPMF\# films do not inhibit the proliferation of HDFs. For a quantitative analysis of the biocompatibility, the viability of HDFs on the C-PHPCMF\# films was obtained by measuring the optical density at $540 \mathrm{~nm}$ after treatment of the neutral red dye. Fig. 6(c) shows the superior viability of HDFs on all the
C-PHCPMF\# films to that of bare glass; in particular, C-PHCPMF5 and C-PHCPMF10 films exhibit excellent cell viability after 4 days. The cytotoxicity of the C-PHCPMF\# films was also evaluated using a qualitative assay of live/dead cells, wherein live and dead cells were stained green and red, respectively. Fig. 7 shows that almost all HDFs are alive with no (a)

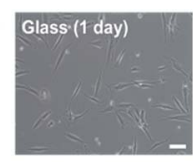

(b)

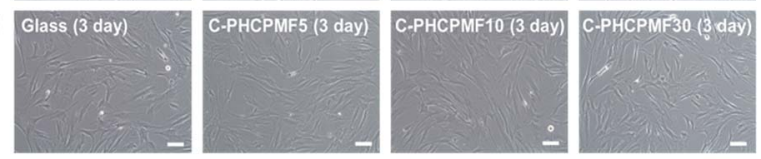

(c)

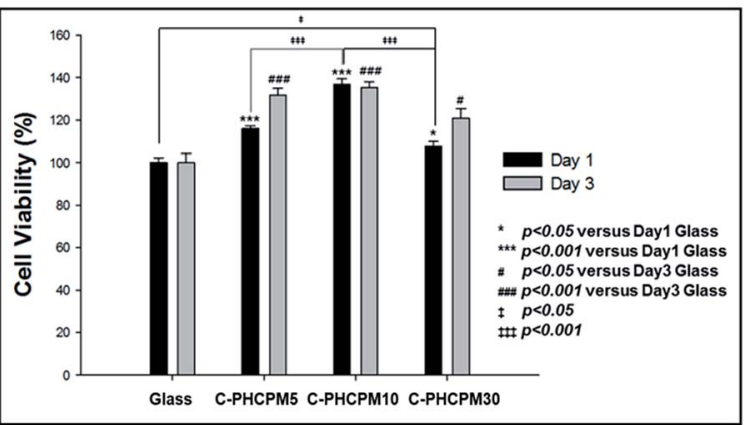

Fig. 6 Representative optical microscope images of HDFs cultured for (a) 1 and (b) 3 days on the surfaces of the C-PHCPMF\# and glass (scale bar $=100 \mu \mathrm{m}$ ). (c) Cell viability determined by neutral red assay after 1 and 3 days. (a)

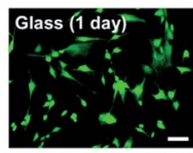

(b)

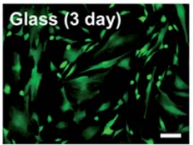

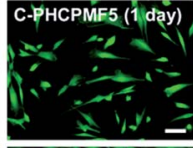

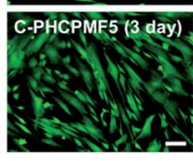

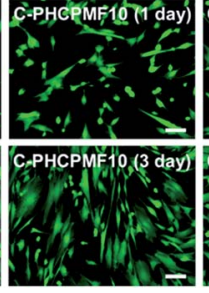

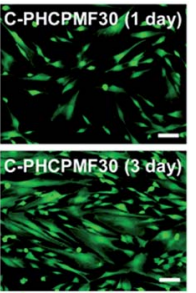

Fig. 7 CLSM images presenting FDA/EB staining on HDFs cultured for 1 and 3 days on C-PHCPMF\# films and glass substrate (scale bar $=100$ $\mu \mathrm{m})$. 
apparent red signals from any of the C-PHCPMF\# films at 1 and 3 days after seeding, indicating that none of the C-PHCPMF\# films shows any cytotoxic behavior on their surfaces.

\section{Conclusions}

ABA-triblock copolymers (PHCPMF\#s) composed of B block with plant-based cardanol moiety and A blocks with perfluoropolyether (PFPE) moiety were prepared via ATRP, and the composition of the copolymer was controlled using different amounts of 2-hydroxy-3-cardanylpropyl methacrylate (HCPM) as a monomer, and modified PFPE as a macroinitiator. Physically stable triblock copolymer films were prepared through UV irradiation on the spin-coated PHCPMF\# films by the reaction between unsaturated hydrocarbons in the HCPM moiety, resulting in the formation of cross-linked structure. The crosslinked PHCPMF film containing about two HCPM units in the B block units showed excellent bactericidal property, bacterial adhesion resistance, and cell viability, because it contained an optimum amount of bactericidal cardanol units, and sufficient amount of antifouling and biocompatible PFPE units. Therefore, we believe that the triblock copolymers containing PFPE and plant-based cardanol moiety are a new material that has bactericidal property and bacterial adhesion resistance, as well as good biocompatibility. Additionally, this study can provide a new way to develop linear PFPE copolymers with good solubility, processability, and multi-functionality for various applications. The conclusions section should come in this section at the end of the article, before the acknowledgements.

\section{Acknowledgements}

This research was supported by the Technology Innovation Program (Grant No. 10045221) and the National Research Foundation of Korea (NRF-2016R1D1A1A02937104).

\section{Notes and references}

1 G. Ducel, J. Fabry and L. Nicolle, Prevention of hospital acquired infections: a practical guide, 2002.

2 M. Shirtliff and J. G. Leid, The role of biofilms in device-related infections, Springer, 2009.

3 G. D. Bixler and B. Bhushan, Philos. Trans. R. Soc., A, 2012, 370, 2381.

4 J. P. Rolland, R. M. Van Dam, D. A. Schorzman, S. R. Quake and J. M. DeSimone, J. Am. Chem. Soc., 2004, 126, 2322.

5 R. Brady, S. Bonafede and D. Schmidt, Surf. Coat. Int., 1999, 82, 582.

6 K. Li, P. Wu and Z. Han, Polymer, 2002, 43, 4079-4086.

7 C. Tonelli, P. Gavezotti and E. Strepparola, J. Fluorine Chem., 1999, 95, 51.

8 E. Molena, C. Credi, C. De Marco, M. Levi, S. Turri and G. Simeone, Appl. Surf. Sci., 2014, 309, 160.

9 A. Priola, R. Bongiovanni, G. Malucelli, A. Pollicino, C. Tonelli and G. Simeone, Macromol. Chem. Phys., 1997, 198, 1893.
10 Y. Wang, L. M. Pitet, J. A. Finlay, L. H. Brewer, G. Cone, D. E. Betts, M. E. Callow, J. A. Callow, D. E. Wendt and M. A. Hillmyer, Biofouling, 2011, 27, 1139.

11 Y. Wang, D. E. Betts, J. A. Finlay, L. Brewer, M. E. Callow, J. A. Callow, D. E. Wendt and J. M. DeSimone, Macromolecules, 2011, 44, 878.

12 Z. Hu, J. A. Finlay, L. Chen, D. E. Betts, M. A. Hillmyer, M. E. Callow, J. A. Callow and J. M. DeSimone, Macromolecules, 2009, 42, 6999.

13 V. A. Schulte, Y. Hu, M. Diez, D. Bünger, M. Möller and

M. C. Lensen, Biomaterials, 2010, 31, 8583.

14 E. R. Kenawy, F. I. Abdel-Hay, A. E. R. R. El-Shanshoury and M. H. El-Newehy, J. Polym. Sci., Part A: Polym. Chem., 2002, 40, 2384.

15 G. Lu, D. Wu and R. Fu, React. Funct. Polym., 2007, 67, 355. 16 D. Roy, J. S. Knapp, J. T. Guthrie and S. Perrier, Biomacromolecules, 2007, 9, 91.

17 J. Cleveland, T. J. Montville, I. F. Nes and M. L. Chikindas, Int. J. Food Microbiol., 2001, 71, 1.

18 G. Nychas, in New methods of food preservation, Springer, 1995, p. 58.

19 V. E. Tikhonov, E. A. Stepnova, V. G. Babak, I. A. Yamskov, J. Palma-Guerrero, H.-B. Jansson, L. V. Lopez-Llorca, J. Salinas, D. V. Gerasimenko and I. D. Avdienko, Carbohydr. Polym., 2006, 64, 66.

20 J. Hasan, R. J. Crawford and E. P. Ivanova, Trends Biotechnol., 2013, 31, 295.

21 M. Himejima and I. Kubo, J. Agric. Food Chem., 1991, 39, 418. 22 Y.-S. Choi, K.-H. Kim, D.-G. Kim, H. J. Kim, S.-H. Cha and J.-C. Lee, $R S C A d v .$, 2014, 4, 41195.

23 Y.-S. Choi, H. Kang, D.-G. Kim, S.-H. Cha and J.-C. Lee, ACS Appl. Mater. Interfaces, 2014, 6, 21297.

24 Z. Cao and Y. Sun, ACS Appl. Mater. Interfaces, 2009, 1, 494.

25 N. Bordenave, S. Grelier and V. Coma, Biomacromolecules, 2009, 11, 88.

26 W.-R. Li, X.-B. Xie, Q.-S. Shi, H.-Y. Zeng, O.-Y. You-Sheng and Y.-B. Chen, Appl. Microbiol. Biotechnol., 2010, 85, 1115.

27 D. Kaelble, J. Adhes., 1970, 2, 66.

28 D. K. Owens and R. Wendt, J. Appl. Polym. Sci., 1969, 13, 1741.

29 A. Milani, J. Zanetti, C. Castiglioni, E. Di Dedda, S. Radice, G. Canil and C. Tonelli, Eur. Polym. J., 2012, 48, 391.

30 D.-G. Kim, H. Kang, Y.-S. Choi, S. Han and J.-C. Lee, Polym. Chem., 2013, 4, 5065.

31 D.-G. Kim, H. Kang, S. Han and J.-C. Lee, ACS Appl. Mater. Interfaces, 2012, 4, 5898.

32 G. John and C. K. S. Pillai, Macromol. Rapid Commun., 1992, 13, 255.

33 G. John and C. Pillai, J. Polym. Sci., Part A: Polym. Chem., 1993, 31, 1069.

34 N. A. Porter, S. E. Caldwell and K. A. Mills, Lipids, 1995, 30, 277.

35 V. Tychopoulos and J. H. Tyman, J. Sci. Food Agric., 1990, 52, 71.

36 W. J. Yang, T. Cai, K.-G. Neoh, E.-T. Kang, G. H. Dickinson, S. L.-M. Teo and D. Rittschof, Langmuir, 2011, 27, 7065. 
37 J. Jiang, L. Zhu, L. Zhu, H. Zhang, B. Zhu and Y. Xu, ACS Appl. Mater. Interfaces, 2013, 5, 12895.

38 X. Ding, C. Yang, T. P. Lim, L. Y. Hsu, A. C. Engler, J. L. Hedrick and Y.-Y. Yang, Biomaterials, 2012, 33, 6593.

39 R. E. Baier, J. Mater. Sci.: Mater. Med., 2006, 17, 1057.

40 J. Genzer and K. Efimenko, Science, 2000, 290, 2130.
41 D. L. Schmidt, R. F. Brady, K. Lam, D. C. Schmidt and M. K. Chaudhury, Langmuir, 2004, 20, 2830.

42 R. F. Brady, Prog. Org. Coat., 1999, 35, 31.

43 J. Gao, D. Yan, H. Ni, L. Wang, Y. Yang and X. Wang, J. Colloid Interface Sci., 2013, 393, 361.

44 J. C. Yarbrough, J. P. Rolland, J. M. DeSimone, M. E. Callow, J. A. Finlay and J. A. Callow, Macromolecules, 2006, 39, 2521. 